Louisiana State University

LSU Digital Commons

LSU Master's Theses

Graduate School

March 2020

\title{
Mental Health Help-Seeking in Adolescence: An Exploration of Variables Associated with Help-Seeking Intent in Schools
}

Sam Allouche

Follow this and additional works at: https://digitalcommons.Isu.edu/gradschool_theses

Part of the Child Psychology Commons, Developmental Psychology Commons, and the School Psychology Commons

\section{Recommended Citation}

Allouche, Sam, "Mental Health Help-Seeking in Adolescence: An Exploration of Variables Associated with Help-Seeking Intent in Schools" (2020). LSU Master's Theses. 5073.

https://digitalcommons.Isu.edu/gradschool_theses/5073

This Thesis is brought to you for free and open access by the Graduate School at LSU Digital Commons. It has been accepted for inclusion in LSU Master's Theses by an authorized graduate school editor of LSU Digital Commons. For more information, please contact gradetd@lsu.edu. 


\title{
MENTAL HEALTH HELP-SEEKING IN ADOLESCENCE: AN EXPLORATION OF VARIABLES ASSOCIATED WITH HELP- SEEKING INTENT IN SCHOOLS
}

\author{
A Thesis \\ Submitted to the Graduate Faculty of the \\ Louisiana State University and \\ Agricultural and Mechanical College \\ in partial fulfillment of the \\ requirements for the degree of \\ Master of Arts \\ in
}

The Department of Psychology

\author{
by \\ Sam Allouche \\ Louisiana State University \\ B.S., Tulane University, 2011 \\ M.S. Tulane University, 2016
}

May 2020 


\section{TABLE OF CONTENTS}

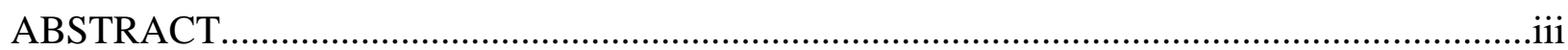

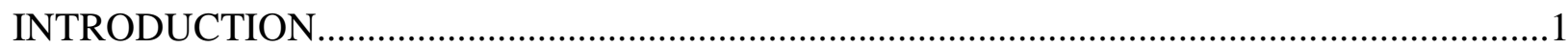

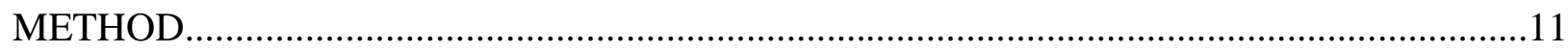

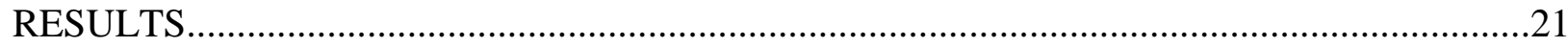

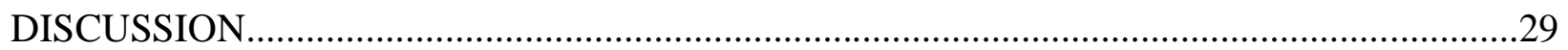

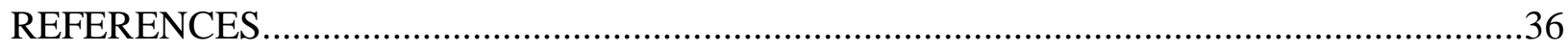

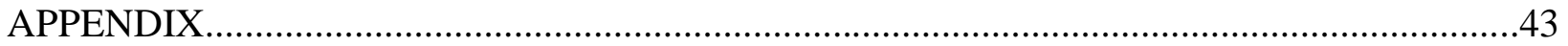

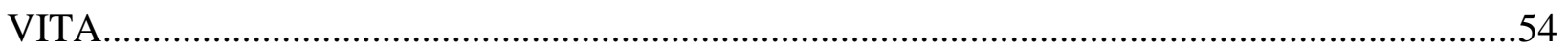




\begin{abstract}
Internalizing disorders (including anxiety and depressive disorders) affect up to one third of adolescents ages 13-18. Although these disorders are associated with impairments in psychological, academic, social, and family domains, they are often left untreated. Schools have great potential to address this service-underutilization gap by identifying those students at risk for internalizing problems through mental health screening tools and by providing treatment at no cost for students. However, at the secondary level, school personnel partly expect high school students to initiate support for themselves. The present study advances research by exploring the variables related to adolescent mental health help-seeking intentions within the school setting. Specifically, this study assesses the utility of the Theory of Planned Behavior in an effort to identify what factors relate to high school students' willingness to seek help for internalizing problems at school. A secondary aim of this study was to examine why males are consistently less willing to seek help for mental health problems than females. Results of this study highlight important factors to target when developing interventions to increase help-seeking intent in high school students.
\end{abstract}




\section{INTRODUCTION}

Internalizing disorders (e.g., anxiety disorders, depressive disorders) are prevalent in approximately one third of youth ages 13-18 (Kessler, Chiu, Demler, \& Walters 2005;

Merikangas et al., 2010). These disorders are often characterized by quiet, internal distress, and are associated with poorer academic, social, physical, and family functioning (Tandon, Cardeli, \& Luby, 2009; Sulkowski, Joyce \& Storch, 2012). Specifically, adolescents with internalizing symptoms are at increased risk for later major depression, anxiety disorders, substance use and abuse, educational underachievement, unemployment and early parenthood (Fergusson \& Woodward, 2002). Separate studies have also shown that the presence of depression and anxiety symptoms in adolescence were associated with low family functioning and predicted lower grade point averages (GPA; Simpson, Vannucci \& Ohannessian, 2018; Weidman, Augustine, Murayama, \& Elliot, 2015).

Treatment of these disorders is imperative to preventing future life impairment and reducing health care costs nationwide. Unfortunately, despite the high prevalence and associated negative effects, internalizing disorders are often left untreated (World Health Organization [WHO], 2017). As most mental health problems have an onset in early adolescence and young adulthood, high schools present a unique opportunity to target early symptoms of distress in youth (WHO, 2017). Not only does the school setting eliminate practical barriers commonly associated with seeking treatment (e.g., cost, and travel), but the school setting also enables personnel to witness students' functioning (academic, social, and otherwise) firsthand.

At the secondary level, universal mental health screening remains inconsistent. Instead, schools often rely on students to initiate support for themselves, an expectation consistent with adolescents' developmental maturation toward independence, or, more typically, schools use 
office discipline referrals to identify students at-risk for emotional-behavioral disorders (Kalberg, Lane, \& Menzies, 2010). Although common, the use of office discipline referrals is problematic because they are applied inconsistently across schools in the U.S. (Naser, Brown, \& Verlenden, 2018). Additionally, the use of office discipline referrals fails to detect non-disruptive, internalizing symptoms and further minimizes the significance of internalizing problems and important need for early intervention (Splett et al., 2018). Moreover, even when schools use valid mental health screeners, these are often administered on a twice a year basis, leaving the possibility of missing symptoms or crises that arise between screenings entirely (Prochaska, Le, Baillargeon, \& Temple, 2016; Severson, Walker, Hope-Doolittle, Kratochwill, \& Gresham, 2007). Therefore, the purpose of this study is to extend the literature on school mental health practice by gaining an understanding about what variables affect students' willingness to seek support for internalizing problems in schools. By gaining this knowledge, schools can best optimize the pathways to service utilization for their students.

\section{Predicting Help-Seeking}

Theory of planned behavior. The Theory of Planned Behavior (TPB; Ajzen, 1985, 1991) is one explanatory model that is used to predict a wide variety of health behaviors from help-seeking, to smoking cessation, to healthy eating habits (Bohon, Cotter, Kravitz, Cello \& Garcia, 2016). According to the TPB, intention or willingness to perform a behavior is the direct antecedent to performing that behavior. Intentions capture the extent of an individual's motivational effort or willingness to engage in a behavior. The TPB (Ajzen, 1991) purports that behavioral intention is determined by three factors: attitudes (ATT), subjective norms (SN), and perceived behavioral control (PBC). ATT, according to the TPB, are shaped by an individual's behavioral beliefs about engaging in a particular behavior (or attitudes toward a behavior). 
Specifically, ATT reflect an individual's beliefs about the potential outcome from that behavior. Not surprisingly, an individual will come to favor behaviors that have more desirable outcomes and will view behaviors with negative consequences unfavorably. ATT about seeking help are consistently the strongest predictor of help-seeking intention (Cramer, 1999; Li, Dorstyn, \& Denson, 2014; Schnyder, Panczak, Groth, \& Schultze-Lutter, 2017).

$\mathrm{SN}$, the second antecedent to intentions in the TPB, are shaped by a person's normative beliefs, which represent perceived social pressure to engage (or not engage) in a behavior. Put another way, normative beliefs are shaped by the perceived approval (or disapproval) from important social referents for engaging in a behavior (Ajzen, 1991; Long \& Maynard, 2013). Social referents may include peers, family members, and significant others. Subjective norms are further distinguished by two norm subtypes: injunctive and descriptive norms. Injunctive norms explain that typically, people are more likely to perform a behavior when their social referents believe they should, while descriptive norms explain that people are also more likely to engage in a behavior that their social referents engage in as well. Although subjective norms have had inconsistent value in predicting mental health help-seeking, they are potentially of greater significance in adolescence, where peer salience and pressure from social evaluation are especially high (Cramer, 1999; Armitage \& Conner, 2001; Clement et al., 2015).

$\mathrm{PBC}$ is the third and final predictor in the TPB and reflects the perceived ease (or difficulty) of performing a behavior. Specifically, PBC is said to be shaped by an individual's control beliefs and addresses behaviors that are beyond an individual's volitional control. Just as intentions represent an individual's motivational effort in performing a behavior, $\mathrm{PBC}$ encompasses the non-motivational elements that affect the likelihood of behavioral engagement. Therefore, $\mathrm{PBC}$ plays a direct role in behavior prediction, to the extent that an individual's 
perceptions reflect his/her actual capacity to engage in a behavior (Ajzen 1991; Armitage \& Conner, 2001; Long \& Maynard, 2013). Mental health help-seeking in the United States is a behavior often beyond an individual's immediate control due to imposed structural barriers (e.g., cost, travel, health insurance, etc.). Although barriers have shown significant association to helpseeking intentions in the past (e.g., Gulliver, Griffiths, \& Christenson, 2010), seeking mental health treatment within the high school setting where a mental health professional is available should eliminate some of the structural barriers otherwise present in community and adult populations.

Other variables associated with help-seeking. Though the TPB explains a significant portion of variance in help-seeking intentions, it is by no means intended to provide a sufficient model for behavioral predictions. In fact, the explanatory power of the TPB has been moderate at best, roughly accounting for $28-40 \%$ of the variance in help-seeking intentions (Rise, Sheeran, \& Hukkelberg, 2010; Armitage \& Conner, 2001; Godin \& Kok, 1996; Sheeran \& Taylor, 1999). Fortunately, Ajzen (1991) never suggested his model would sufficiently and uniquely account for all possible influences on behavioral intention and appropriately supported the inclusion of other predictors as long as they account for additional variance in behavioral intention. Therefore, it is important for us to consider some other previously identified contributors from the mental health help-seeking literature.

Importantly, most research on help-seeking behavior is conducted in community, clinical, or college/university samples. Thus, the generalizability of trends related to mental health helpseeking is limited by the samples and settings represented in investigations to date. Although research in the aforementioned populations is instrumental to informing the present study, it cannot definitively translate to the adolescent population within the school context. Indeed, 
adolescence presents a unique developmental period comprised of hormonal, physical, and social changes which undoubtedly shape the way humans understand themselves and interact in the world. Not only can the rapid developmental changes associated with adolescence contribute to the onset of mental health problems during this period (Walker, Bell, Flores, Gulley, Willing, \& Paul, 2017), they may also be associated with different trends in adolescents' willingness to engage in help-seeking. As a result, the inclusion of additional variables (beyond those outlined in the TPB) are important to our model to predict help-seeking intention as this ensures all relevant factors are included that might explain adolescents' mental health help-seeking in schools (i.e., factors based on past theory and research, as well as relevant to the present study sample).

Past behavior. One variable that is often considered in behavioral prediction models is history of behavior engagement (Hagger, Polet, \& Lintunen, 2018; Horwitz, Czyz, \& King, 2015; Ouellette \& Wood, 1998). Certainly, prior engagement in mental health services is expected to impact future willingness to engage in mental health help-seeking. However, Ajzen (1991) emphasized that if prior behavior contributes to model accuracy, then this signifies that there are likely other factors that have not been accounted for in the prediction of behavioral intent. In this sense, past behavior should be used to test model factor sufficiency, as anything beyond a small residual effect from inclusion of behavioral history would suggest a less than sufficient model (Ajzen, 1991). In this way, significant variance explained in mental health helpseeking intent from the inclusion of past behavior will reveal the potential inadequacy of the prediction model.

Symptom severity. Symptom severity has a demonstrative impact on mental health helpseeking in that greater symptom severity relates to greater mental health help-seeking intention 
(Bradley, McGrath, Brannen, \& Bagnell, 2010). This makes some intuitive sense, in that one would expect someone with presenting mental health problems to be more likely to intend to seek help than someone without any mental health problems. However, it is important to recognize the typical symptom pattern in someone with internalizing problems which may include low motivation, social withdrawal, and indecisiveness. For example, an individual with depression will have inhibited proactive help-seeking based on their current behavioral and psychological symptoms. This phenomenon, referred to as help-negation, worsens with symptom severity (Wilson \& Deane, 2010; Thomas \& Larkin, 2018). In this way, it is possible that greater symptom severity increases mental health help-seeking intention in some while inhibiting it in others.

Mental health literacy. Mental health literacy (MHL) refers to the extent to which an individual accurately recognizes their symptoms as indicative of an underlying psychological problem (Wei, McGrath, Hayden, \& Kutcher, 2015). Several studies have shown that increased MHL contributes to greater mental health help-seeking intention (Swords, Hennessy, \& Heary, 2011; Lee, Friesen, Walker, Colman, \& Donlan, 2012; Singh, Zaki, \& Farid, 2019). Moreover, several studies have shown that individuals with suicidal ideation and thoughts might not recognize their problems, yet may require professional help (Hom, Stanley, \& Joiner, 2015). Specifically, Downs \& Eisenberg (2012) found that in suicidal college students, individuals believed their symptoms and related stress were normal parts of the college experience. Additionally, a WHO national survey found that low perceived need for treatment was one of the most significant reasons why individuals did not seek treatment (Bruffaerts et al., 2011). If these trends are present in older populations, then it is quite likely they are present in adolescent, high 
school students for whom pathological changes in emotion, mood, and psychological experience are confounded with other developmentally normative changes.

Sex. The proportion of students with internalizing disorders in adolescence is higher in females than in males (Alloy, Hamilton, Hamlat, \& Abramson, 2016). However, research shows that males also underutilize mental health treatment compared to their female counterparts, even when controlling for symptomatology. Much of the literature attempting to explain this gap in treatment seeking has been conducted with males (e.g., Addis \& Mahalik, 2003; Steinfeldt \& Steinfeldt, 2010; Himmelstein \& Sanchez, 2016), as they are the service under-utilizers. This research has identified a general conformity to masculine gender norms or an adherence to "traditional masculine behavior" (Juvrud \& Rennels, 2016, p. 28) as the primary reason for the discrepancy in mental health help-seeking across the sexes. And though an underlying process cannot be confirmed, it has been proposed that proactive help-seeking is socially costly to individuals generally, and men specifically, as it may make them feel inferior to or dependent on others. In this way, it is posited that mental health help-seeking can be seen as a violation of traditionally masculine stereotypes that would more typically endorse self-reliance, stoicism, toughness and superiority. Therefore, it is possible that sex differences in mental health helpseeking can be explained by differences in gender role conformity.

Externalizing Symptoms. Though internalizing symptoms sometimes materialize in adolescence in a pure form, oftentimes, withdrawal, anxiety, fearfulness and depression co-occur along with hyperactivity, aggression, defiance, and destructive behavior (i.e., externalizing symptoms; Fonti \& Henrich, 2010; Gilliom \& Shaw, 2004). Previous research revealed the cooccurrence of internalizing and externalizing symptoms in youth occurs at a rate greater than what could be expected by chance and is associated with worse developmental outcomes than 
those presenting with just one diagnosis (Oland \& Shaw, 2005). Given the moderately high comorbidity rate between internalizing and externalizing disorders in youth, and the unique risks associated with this occurrence, it is important to consider externalizing symptomatology and its potential impact on help-seeking intent for teens.

\section{Study Purpose}

The present study contributes to existing research on mental health help-seeking in adolescence in several ways. First, there has been little investigation into help-seeking for internalizing symptoms within a high school setting (Wilson, Rickwood, \& Dean, 2007; Rickwood, Deane, Wilson, \& Ciarrochi, 2005; Zeifman, Atkey, Young, Flett, Hewitt, \& Goldberg, 2015). Wilson et al. (2007) found that those with greater internalizing symptoms were more likely to say they would seek help from no one, while Rickwood et al. (2005) found that males with internalizing symptoms were less likely than females with internalizing symptoms to seek treatment. Zeifman et al. (2015) identified stigma as a barrier to help-seeking in adolescents with internalizing symptoms but found that this effect was moderated by levels of MHL. Although these studies are highly relevant, they are few in number and do not cover all of the salient factors that have shown associations to help-seeking intent in other populations.

Second, to our knowledge, this study was the first to examine the association of variables of the TPB with willingness to seek mental health treatment in a high school setting. Thus far, research using the TPB to predict mental health help-seeking has focused on college-aged samples and clinical samples. Results from these studies have shown trends that may or may not exist in high school populations where physical and psychological development is qualitatively unique. The current study was the first to apply the commonly used behavioral prediction model, the TPB, to explain mental health help-seeking in a secondary school setting. Variables 
comprising the TPB (e.g., ATT, SN, PBC), along with other known factors associated with mental health help-seeking (MHL, sex, symptom severity, prior mental health treatment) were used to gain information about when high school students do (or do not) intend to seek mental health help. There is an urgent need to understand why adolescents seek help for mental health problems, as current systems (e.g., mental health screeners, ODRs) may fail to identify all those in need for treatment and the risk associated with untreated internalizing problems is vast.

Finally, a secondary aim of this study was to examine why males and females differ in their willingness to seek mental health treatment. It is expected that higher conformity to masculine gender norms will relate to lower help-seeking intent in both males and females, but the specific aspects of masculine gender roles that contribute to this unwillingness is still unclear. If we are able to identify specific factors that contribute to the skewed reports of mental health treatment intent by sex, we will be better positioned to address this gap through future intervention.

\section{Research Questions:}

1. What are adolescents' preferences in terms of sources of help-seeking support when they have elevated internalizing symptoms?

Though we were primarily interested in students' willingness to seek help within the high school, we were also interested in assessing high school students preferred sources of support when presenting with internalizing concerns. Previous research has indicated that adolescents with internalizing problems are more likely to seek help from an informal source (e.g., peer or

parent; Arria et al., 2011; Lindsey, Korr, Broitman, Bone, Green, \& Leaf, 2006; Yap, Wright, \& Jorm, 2011). However, beyond the formal/informal distinction, we did not have a hypothesis for 
what specific help-seeking sources adolescents might prefer when presenting with internalizing concerns.

2. Are high school students' attitudes towards, subjective norms about, and perceived behavioral control regarding mental health treatment associated with their willingness to seek treatment in school?

Though we expected variables previously identified in research (e.g., prior treatment, symptom severity, externalizing symptoms, MHL, and sex) to have significant associations with mental health help-seeking intent, we expected the variables associated with the TPB (ATT, SN, and $\mathrm{PBC}$ ) to explain a significant proportion of the variance in high school students' help-seeking intent above and beyond those variables.

3. Are there group differences in willingness to seek mental health help based on student sex? If so, what might explain these differences?

a. Does gender role conformity explain the differences in willingness to seek mental health help based on student sex?

Consistent with previous research (e.g., Alloy et al., 2016), we expected males to report less willingness to seek mental health help than their female counterparts. Further in line with research in this area (e.g., Juvrud \& Rennels, 2016), we expected that a measure of gender role conformity would explain, at least in part, this difference in mental health help-seeking intent by sex. 


\section{METHOD}

\section{Participants and Setting}

An a priori power analysis was conducted using $G^{*}$ Power 3.1 software in order to determine the sample size necessary to achieve a small to medium effect $\left(f_{2}=.15\right)$ with recommended power (.80; Cohen, 1988). The results of this analysis indicated the need for 77 eligible participants. To be eligible for participation, students needed to be in grades nine through 12 and currently enrolled at a recruitment school. There were no further criteria for eligibility. Two schools were recruited for participation in the study. Participants were recruited from two public charter high school(s) in Southern Louisiana. Although two schools accepted, one dropped out due to organizational challenges. All participants in the study attended the remaining charter high school in a city in Southern Louisiana. The school has a total population of 1740 students in grades k-12, and a population of 696 students in the high school. Minority enrollment for the school is $44 \%$, less than the state average of $55 \%$, with $13 \%$ of the school eligible for free or reduced lunch (state average 63\%). 696 students were eligible for participation in the study. Active consent to participate in the study was received for 571 students (82\%). Subsequently 82 students dissented to participate. Therefore, results were gathered for 486 students (70\% of eligible participants).

Student demographics are available in Table 1. Students ranged in age from 13-18 ( $M$ $=15.48 ; S D=1.123)$. The sample consisted of $27.8 \% 9$ th-grade $(n=135), 24.9 \% 10$ th-grade $(n=$ 121), 27.8\% 11th-grade $(n=135)$, and $19.5 \%$ 12th-grade $(n=95)$ students. Participants' racial/ethnic identity was reported as $57.8 \%$ White/Caucasian $(n=281) 22.6 \%$ Black/African American $(n=110), 10.1 \%$ Multi-racial/ethnic $(n=49), 5.6 \%$ Latino(a)/Hispanic $(n=27), 2.7 \%$ Asian/Asian American ( $n=13), 0.2 \%$ Native American/Indigenous $(n=1)$, and 1\% Other $(n=$ 
5). The student sample was comprised of $43.4 \%$ males $(n=211), 53.5 \%$ females $(n=260)$ and $2.9 \%$ gender-diverse/non-conforming and "other" $(n=14)$. Student responses for "other" included the following identities: "trans", "agender", "trans-female", and "figuring it out". Only one student did not enter a valid gender identity and was therefore excluded listwise from corresponding analyses. Finally, 70.6\% $(n=343)$ of students indicated that they had never engaged in mental health treatment, with the remaining $29.4 \%(n=143)$ indicating that they had previously engaged or were currently engaged in mental health treatment. 
Table 1. Participant Demographics

\begin{tabular}{|c|c|c|}
\hline Category & $N$ & $\%$ \\
\hline \multicolumn{3}{|l|}{ Age } \\
\hline 13 & 1 & 0.2 \\
\hline 14 & 120 & 24.7 \\
\hline 15 & 123 & 25.3 \\
\hline 16 & 138 & 28.4 \\
\hline 17 & 95 & 19.5 \\
\hline 18 & 9 & 1.9 \\
\hline Total & 486 & 100 \\
\hline \multicolumn{3}{|l|}{ Grade } \\
\hline 9 th & 135 & 27.8 \\
\hline $10_{\mathrm{th}}$ & 121 & 24.9 \\
\hline $11_{\text {th }}$ & 135 & 27.8 \\
\hline 12 th & 95 & 19.5 \\
\hline Total & 486 & 100 \\
\hline \multicolumn{3}{|l|}{ Race } \\
\hline White Caucasian & 281 & 57.8 \\
\hline Black or African American or Caribbean Black & 110 & 22.6 \\
\hline Multi-Racial or Multi-Ethnic & 49 & 10.1 \\
\hline Latino(a) or Hispanic & 27 & 5.6 \\
\hline Asian or Asian American & 13 & 2.7 \\
\hline Native American or Indigenous & 1 & 0.2 \\
\hline Other & 5 & 1 \\
\hline Total & 486 & 100 \\
\hline \multicolumn{3}{|l|}{ Gender Identity } \\
\hline Female & 260 & 53.6 \\
\hline Male & 211 & 43.5 \\
\hline Gender-diverse/Non-conforming or Other & 14 & 2.89 \\
\hline Total & 485 & 99.79 \\
\hline \multicolumn{3}{|l|}{ Prior Engagement in Mental Health Treatment } \\
\hline Yes & 143 & 29.4 \\
\hline No & 343 & 70.6 \\
\hline Total & 486 & 100 \\
\hline
\end{tabular}




\section{Measures}

Demographic Questionnaire Form. Demographic information on participating students was collected including age, grade, race/ethnicity, and gender identity. Also, students were asked to indicate whether they have ever participated or were currently participating in mental health services by indicating "yes" or "no" (guided by Ajzen, 2006). Though surveys were sent to students' school emails, these were de-identified before analysis so that no identifying information was relayed to the researchers.

Internalizing Symptoms. Participants' internalizing symptoms were measured using the Youth Internalizing Problems Screener (YIPS; Renshaw \& Cook, 2016), a 10-item scale designed to identify students at risk for internalizing problems. Items ask students about the frequency of occurrence of items on a four- point scale ranging from 1 (almost never) to 4 (almost always) and include, "I feel nervous and afraid," and, "I really do not enjoy doing anything anymore". Higher scores on this scale represent greater internalizing symptoms and a cut-score of 21 identifies youth at-risk for internalizing disorders. Though the measure does not yet have large-scale normative data, the initial psychometric evaluation demonstrated that the YIPS has incremental validity over existing internalizing screeners for youth and has reported "good-to-excellent" power for discriminating between secondary school youth with and without internalizing disorders. The internal consistency reliability for the current sample for the YIPS was .90 and, therefore, strong.

Externalizing Symptoms. Externalizing symptoms were assessed using the Youth Externalizing Problems Screener (YEPS; Renshaw \& Cook, 2018), a 10-item scale used to screen students at-risk for broad externalizing problems. Items ask students to rate the frequency various occurrences including, "I break rules whenever I feel like it," and, "I have a hard time 
focusing on things that are important" on a four-point scale ranging from 1 (never) to 4 (almost always). Higher scores represent greater externalizing symptoms with a cut-score of 23 identifying youth at risk for externalizing problems. Initial psychometric properties of this screener suggest a unidimensional factor structure, and evidence of convergent validity with other measures of the same construct (Renshaw \& Cook, 2018). Internal consistency for the current sample was acceptable at .76.

Intent. Participant's intentions to seek psychological help were measured via two methods, one general and one school focused. First, participants were asked to rate their specific intent to seek help from a person within the school setting (e.g., school counselor, administrator, educator) using a single item assessing intent to act delineated by Ajzen (2006) in his guide for constructing a TPB questionnaire. This item asked students to rate the likelihood of the item, "I intend to seek mental health help from someone within the school (e.g., school counselor, teacher, administrator)," with responses on a seven-point scale ranging from 1 (likely) to 7 (not likely). Previous research using a similar scale showed individuals' ratings increased in response to a brief intervention resulting in greater treatment-seeking behavior (Buckner \& Schmidt, 2009) and was subsequently used in a study to assess Black adolescents' help-seeking intent (Dean, Long, Matthews, \& Buckner, 2016). Second, participants' general intent to seek help was assessed using the General Help Seeking Questionnaire (GHSQ; Wilson et al., 2007), a scale that examines respondents' intent to receive help from a variety of sources including a friend, parent, and mental health professional. This scale was the most commonly used in adolescent helpseeking research to assess behavioral intent for mental health help-seeking (Divin, Harper, Curran, Corry, \& Leavey, 2018). Test-re-test reliability for the scores on this measure was high $(\alpha=.92)$, and the reported internal consistency coefficients for the GHSQ are at least adequate, 
ranging from .72 - .99 (Wilson et al., 2007; Wilson \& Deane, 2012; Cakar \& Savi, 2014;

Leshem, Haj-Yahia, \& Guterman, 2015; Beals-Erickson \& Roberts, 2016). The GHSQ is a seven-point Likert scale with answers ranging from 1 (very unlikely) to 7 (very likely), with higher scores indicating a greater intent to seek help. The internal consistency reliability for the GHSQ for this study was found to be .74 and adequate.

Normative Beliefs/Subjective Norm. Participants' normative beliefs were measured using items from the Stigma subscale from the Parental Attitudes Toward Psychological Services Inventory (PATSPI; Turner, 2010). The items were adapted slightly to relate to students and included changes from "I would not want others (friends, family, teachers, etc.) to know if my child had a psychological or behavior problem," to, "I would not want others (friends, family, teachers, etc.) to know if I had a psychological or behavior problem." Psychometric properties of the scale include adequate internal consistency (.72-.92), and test-retest reliability, as well as evidence of discriminant validity. The internal consistency reliability for the Stigma subscale of the PATSPI for this study was found to be .83 and good.

Behavioral Beliefs/Attitudes. Participants' attitudes about seeking psychological help were measured using the Attitudes subscale from the Parental Attitudes Toward Psychological Services Inventory (PATSPI) assessing help-seeking attitudes. Items were adapted slightly so that all items related to students. For example, the item, "to avoid thinking about my child's problems, doing other activities is a good solution," was adapted to state, "to avoid thinking about my problems, doing other activities is a good solution". Items were rated on a six-point scale ranging from 1 (strongly disagree) to 6 (strongly agree). The internal consistency reliability for the Attitudes subscale of the PATSPI for this study was found to be .79 and adequate. 
Gender Role Identity. Gender role conformity was assessed using 16 items from three subscales of the Conformity to Masculine Norms Inventory (CMNI; Mahalik et al., 2003): Emotional Control, Risk-Taking and Self-Reliance. The Risk-Taking subscale relates to a variety of health behaviors (e.g., substance use) and includes items such as, "I enjoy taking risks". The Emotional Control and Self-Reliance scales are associated with negative attitudes towards seeking psychological help (Mahalik et al., 2003). Sample items on the Emotional Control and Self-Reliance scales are, "I tend to keep my feelings to myself," and, "I am not ashamed to ask for help", respectively. Each item is rated on a four-point scale ranging from 0 (strongly disagree) and 3 (strongly agree). Test re-test reliability for these subscales were .90 for Emotional Control, .88 for Risk-Taking, and .80 for Self-Reliance. Internal consistency for each scale was $.91, .82$, and .85 from previous research and $.88, .81, .80$ for the current sample, respectively.

Control Beliefs/Perceived Behavioral Control. Participant's control beliefs were assessed using a brief version of the Barriers to Adolescents Seeking Help Scale (BASH-B; Wilson, Rickwood, Ciarrochi, \& Deane, 2002; Kuhl, Jarkon-Horlick, \& Morrissey 1997). This scale was reduced from its original 37 items to an 11-item self-report measure targeting barriers to seeking professional psychological help. We used a slightly adapted version of the BASH-B so that all items correspond to barriers of help-seeking within a school setting. For example, "Even if I wanted to, I wouldn't have time to see a counsellor," was replaced by "Even if I wanted to, I wouldn't have time to see a school counselor." Items were rated on a six-point scale ranging from 1 (strongly disagree) to 6 (strongly agree). This brief measure had an internal consistency coefficient of .83 and had been repeatedly validated in adolescent samples, (Wilson, Deane, 
Ciarrochi, \& Rickwood, 2005; Wilson \& Deane, 2012). The internal consistency reliability for this study sample was .81 .

Mental Health Literacy. Participants' mental health literacy was assessed using the Mental Health Promoting Knowledge Instrument (MHPK-10; Bjørnsen, Eilertsen, Ringdal, Espnes, \& Moksnes, 2017), a 10-item, single factor scale assessing adolescents' knowledge of mental health promotion. Items state various activities that may relate to positive mental health and ask responders to rate their relative helpfulness on a five-point scale ranging from 1 (definitely unhelpful) to 5 (definitely helpful). Sample items on this scale include, "believing in yourself," and, "having good sleep routines". This scale has demonstrated solid test-retest reliability as well as good construct validity. The internal consistency reliability for the present sample was .86.

\section{Procedures}

All participants were administered a battery of eight measures along with a survey of demographic variables. The order of survey item/scale presentation was carefully considered by the researchers in order to collect mental health symptoms first, before a probe related to helpseeking intent. This decision was made so that emotional and behavioral symptoms were primed for participants to consider more accurately their mental health help-seeking intentions.

Measures were presented to students in the order which they are presented above. Participants were recruited using a two-step recruitment procedure. In step one, we reached out to secondary school administrations related to their interest in participating in a school-wide mental health screening.

In step two (following approval from administration), we received active parental consent for participation in our survey study. Surveys (created with Google Forms) were sent to 
students' school email addresses during the class block designated by the recruited school for mental health screening. No other duties were required of students during the allotted time. Those students whose parents did not consent for them to participate were given a computer task activity to complete during the scheduled block. Study researchers were denied access to the Google Forms survey data prior to administration to protect participant confidentiality.

Following data collection, school personnel replaced participant emails with student ID numbers and researchers were subsequently re-granted access to the spreadsheet of responses. All data was stored on researchers' Google accounts secured through two-factor authentication methods. Researchers were unable to link student data to identifying student information; however, participating schools will so that they can follow up with appropriate services for those they identify as at risk.

\section{Analyses}

Preliminary Analyses. All analyses were conducted using IBM SPSS Statistics software (version 26). First, we assessed the missing data for each variable. There was no missing data to due forced responses on the survey and therefore, no decision was required. Next, we assessed all appropriate variables for violations of assumptions for the primary analyses including normality, linearity, homoscedasticity/homogeneity of variance, and multicollinearity.

Research question one analyses. Frequency counts and percentages were calculated to assess high school students' overall preference for a variety of help-seeking sources (as measured by the YIPS). Next, we calculated the significance of the differences among various help-seeking source preferences between those with and without risk for internalizing disorders.

Research question two analyses. We conducted a hierarchical linear regression to test our hypothesis that variables comprising the TPB will explain intent to seek help in high school 
students. Variables identified in previous research (past behavior, symptom severity, externalizing symptoms, mental health literacy, and sex) were entered in the first step of our regression model. Variables comprising the TPB (ATT, SN, PBC) were entered into the second step of the model to see what added variance they explained in our outcome of interest.

Research question three analyses. We conducted an independent samples t-test to assess whether males and females differed significantly in their willingness to seek psychological help in the school setting. Then, three separate simple mediation models were created to see if the CMNI subscales, Emotional Control, Risk-Taking, and Self-Reliance, explained the difference in help-seeking intent by student sex. For each mediation, we followed the steps outlined by Baron and Kenny (2006). In step one we tested the association of sex on willingness to seek help within the school. In step two, we tested the association of sex on the three CMNI subscales. In the third step, we included the CMNI subscales in separate regression models to test the effects of sex on willingness to seek help. Finally, we tested the statistical significance of the mediation using the Sobel Test (Sobel, 1982). 


\section{RESULTS}

Descriptive statistics and preliminary analyses were conducted on demographic and study variables to ensure all assumptions for primary analyses were met. Data for each study measure were checked for missing values and no missing data was found. Also, study variables were examined for violations of the assumptions for the primary analyses including normality, linearity, homoscedasticity/ homogeneity of variance and multicollinearity.

\section{Descriptive Statistics}

Table 2 presents descriptive statistics for all study measures. On average, participants reported a low likelihood to seek help at school $(M=2.08 ; S D=1.58)$. A measure of positive mental health awareness via the MHPKI yielded high results from the sample, suggesting the participants reported having a good overall concept of what activities translate to positive mental health $(M=41.95 ; S D=6.38)$. Descriptive statistics of the mental health screeners, YIPS and YEPS, are available in Table 3. 
Table 2. Descriptive Statistics

\begin{tabular}{lcc}
\hline & Survey Measure & $M(S D)$ \\
\hline YIPS & $19.52(6.31)$ \\
YEPS & $14.81(3.72)$ \\
Intent & $2.08(1.58)$ \\
PATSPI & \\
Attitudes & $22.72(7.28)$ \\
Stigma & $24.15(8.26)$ \\
CMNI-46 & \\
Risk-Taking & $17.658(5.19)$ \\
Self-Reliance & $14.737(5.02)$ \\
Emotional Control & $16.268(6.01)$ \\
BASH-B & $33.10(9.316)$ \\
MHPKI & $41.95(6.38)$ \\
\hline
\end{tabular}

Note: Higher scores on the YIPS indicate greater internalizing symptoms. Higher scores on the YEPS indicated greater externalizing symptoms. Intent measured intent to seek help at school ranging from 1 (very unlikely) to 7 (very likely). Higher scores on the three subscales from the CMNI-46, Risk-Taking, Self-Reliance and Emotional Control, indicate greater agreement with the subscale categories. Higher scores on the BASH-B relate to greater endorsement of barriers to seeking help. MHPKI assesses participants' level of agreement with activities related to important mental health promotion with higher scores indicating greater agreement.

Table 3. Mental Health Screening Results

\begin{tabular}{lcc}
\hline \multicolumn{1}{c}{ Category } & $N$ & $\%$ \\
\hline Internalizing Symptoms & & \\
At-Risk & 190 & 39.1 \\
Low- or No-Risk & 296 & 60.9 \\
Total & 486 & 100 \\
& & \\
Externalizing Symptoms & 4 & 0.8 \\
At-Risk & 482 & 99.2 \\
Low- or No-Risk & 486 & 100 \\
Total & & \\
\hline
\end{tabular}

Note: Internalizing symptoms were measured by the Youth Internalizing Problems Screener (YIPS). A cut-score of $\geq 21$ indicates a score in the at-risk range. Externalizing symptoms were measured by the Youth Externalizing Problems Screener (YEPS). A cut-score of $\geq 23$ indicates a score in the at-risk range. 
Internalizing Symptoms. A score of 21 or higher on the YIPS indicates a score in the at-risk range (Renshaw \& Cook, 2016). YIPS total scores ranged from 10 to $40(M=19.52 ; S D=$ 6.307). Results of the YIPS indicated that 39.1\% $(n=190)$ of students endorsed internalizing problems in the at-risk range, with the remaining $60.9 \%(n=296)$ reporting symptoms in the no or low-risk range. There were significant differences in internalizing symptoms by gender identity with males reporting the lowest level of internalizing symptoms $(M=17.63 ; S D=$ $5.824)$, followed by females $(M=20.72 ; S D=6.210)$, with the highest reports of internalizing symptoms in the gender-diverse category $(M=26.29 ; S D=5.539)$.

Externalizing Symptoms. A score of 23 or higher on the YEPS indicates a score in the at-risk range (Renshaw \& Cook, 2018). YEPS total scores ranged from 10 to $31(M=14.81 ; S D$ $=3.723)$. Results of the YEPS indicated that $0.8 \%(n=4)$ of students endorsed externalizing symptoms in the at-risk range, and the remaining $99.2 \%(n=482)$ were screened as not-at-risk. Of the 4 students who endorsed significant externalizing problems, two were male and two were female.

\section{Research Question 1}

Overall and between group help-seeking preferences for the student sample with and without risk for internalizing problems can be found in Table 4. The most-preferred help-seeking source for those screened at-risk for internalizing problems was, "Friend" $(M=4.87 ; S D=$ 1.846), followed by "boy/girlfriend" $(M=3.88 ; S D=2.184)$, followed next by the option, "Would not seek help" $(M=3.84 ; S D=2.189)$. The least common sources of support for youth with internalizing problems include "Religious Leader" ( $M=1.46 ; S D=1.144)$, "Help Line" ( $M$ $=1.74 ; S D=1.347)$, and "Youth Worker/Mentor" $(M=1.79 ; S D=1.525)$. Statistically significant differences between those at-risk for internalizing problems and those not at-risk 
occurred between the following sources: "Parent" ( $F=23.929 ; p=0.000)$, "Non-Parent Family" $(F=17.281 ; p=0.000)$, "Helpline" $(F=8.478 ; p=0.004)$, "Teacher" $(F=4.925 ; p=0.027)$

"Religious Leader" $(F=15.327 ; p=0.000)$ and "Would not Seek Help" $(F=9.390 ; p=0.002)$.

In all cases, the group at-risk for internalizing problems indicated a lower likelihood to seek help.

Table 4. Preferences for Sources of Help-Seeking

\begin{tabular}{lcccccccc}
\hline \multirow{2}{*}{ Source } & \multicolumn{2}{c}{ Overall } & \multicolumn{2}{c}{ At-Risk } & \multicolumn{2}{c}{ Not At-Risk } & & \\
\cline { 2 - 7 } Boy/Girlfriend & $M$ & $S D$ & $M$ & $S D$ & $M$ & $S D$ & $F$ & $p$ \\
Friend & 3.96 & 2.213 & 3.88 & 2.184 & 4.01 & 2.234 & 0.395 & 0.530 \\
Parent & 4.87 & 1.846 & 4.76 & 1.869 & 4.95 & 1.831 & 1.134 & 0.287 \\
Non-parent Family & 3.14 & 1.982 & 2.68 & 1.842 & 3.43 & 2.016 & 17.281 & 0.000 \\
School Counselor & 2.74 & 1.794 & 2.59 & 1.764 & 2.84 & 1.809 & 2.348 & 0.126 \\
Helpline & 2.00 & 1.583 & 1.74 & 1.347 & 2.16 & 1.700 & 8.478 & 0.004 \\
Doctor & 2.76 & 1.953 & 2.64 & 1.891 & 2.84 & 1.992 & 1.162 & 0.281 \\
Teacher & 2.44 & 1.727 & 2.23 & 1.589 & 2.58 & 1.798 & 4.925 & 0.027 \\
Religious Leader & 1.78 & 1.483 & 1.46 & 1.144 & 1.99 & 1.633 & 15.327 & 0.000 \\
Youth Worker/Mentor & 1.79 & 1.631 & 1.79 & 1.525 & 2.25 & 1.673 & 9.390 & 0.002 \\
Would Not Seek Help & 3.24 & 2.030 & 3.84 & 2.189 & 2.86 & 1.825 & 28.734 & 0.000 \\
\hline
\end{tabular}

Note: Preferences for help-seeking sources were rated from 1 (very unlikely) to 7 (very likely). 


\section{Research Question 2}

A stepwise, hierarchical linear regression was conducted in order to test the utility of the variables of the TPB in high schoolers' willingness to seek help above and beyond variables previously identified through research. VIF values were well below 5 and the tolerance statistics were well above .02; therefore, we concluded that was no multicollinearity within the data and proceeded to the regression (Field, 2013). In the first step, variables previously identified by research were entered into the model (past behavior, sex, mental health literacy, symptom severity, and externalizing problems). When the outcome was intent to seek help at school, variables entered in the first step were variables previously identified associations in research: past behavior, student sex, internalizing symptom severity, externalizing symptoms, mental health literacy and prior mental health treatment. Step one of the regression model yielded a significant result, with variables previously identified explaining $20.7 \%$ of the variance in intent to seek help at school $(F(5,479)=25.027)$.

In the second step of the regression, variables associated with the TPB were entered into the model (ATT, SN, \& PBC) with a result of an additional $4.2 \%$ of variance explained above and beyond the first step $\left(R_{2}=.249 ; F(3,476)=19.806 ; p=0.000\right)$. Though both steps in the model were statistically significant, internalizing problems and past behavior were the only significant individual contributors to the model in step $1(\beta=0.297 ; p=0.000 ; \beta=0.175 ; p=$ 0.000). In step $2, \mathrm{PBC}$ was added as a third significant independent contributor $(\beta=-0.175 ; p=$ 0.005). Variable coefficients and standard errors are displayed in Table 5. A regression model summary is displayed in Table 6 . 
Table 5. Stepwise Hierarchical Regressiona

\begin{tabular}{lcccccc}
\hline & \multicolumn{2}{c}{$\begin{array}{l}\text { Unstandardized } \\
\text { Coefficients }\end{array}$} & $\begin{array}{c}\text { Standardized } \\
\text { Coefficients }\end{array}$ & \multicolumn{2}{c}{ Significance } & Correlations \\
\hline \multicolumn{1}{c}{ Model } & $b$ & $S E$ & $\beta$ & $t$ & $p$ & Zero-order \\
& & & & & & \\
(Constant) & -9.38 & 0.585 & & -1.604 & 0.109 & .394 \\
Externalizing Symptoms & 0.021 & 0.021 & 0.050 & 1.010 & 0.313 & .256 \\
Internalizing Symptoms & 0.074 & 0.013 & 0.295 & 5.672 & 0.000 & -.021 \\
Past Behavior & 0.733 & 0.153 & 0.212 & 4.802 & 0.000 & .181 \\
Mental Health Literacy & 0.020 & 0.010 & 0.080 & 1.899 & 0.058 & .332 \\
Student Sex & 0.142 & 0.124 & 0.050 & 1.148 & 0.252 & \\
& & & & & \\
2 & & & & & & \\
(Constant) & 0.187 & 0.625 & & & & \\
Externalizing Symptoms & 0.031 & 0.020 & 0.073 & 1.502 & 0.134 & .394 \\
Internalizing Symptoms & 0.097 & 0.014 & 0.389 & 7.123 & 0.000 & .256 \\
Past Behavior & 0.600 & 0.153 & 0.174 & 3.920 & 0.000 & -.021 \\
Mental Health Literacy & 0.014 & 0.010 & 0.055 & 1.329 & 0.184 & .181 \\
Student Sex & 0.126 & 0.129 & 0.044 & 0.980 & 0.328 & .332 \\
ATT & -0.011 & 0.011 & -0.053 & -1.053 & 0.577 & -.119 \\
SN & -0.006 & 0.011 & -0.032 & -0.558 & 0.293 & -.035 \\
PBC & -0.030 & 0.011 & -0.178 & -2.847 & 0.005 & -.019 \\
\hline
\end{tabular}

a Dependent Variable: Intent to Seek Help at School. 
Table 6. Model Summarya

\begin{tabular}{lccccc}
\hline \multicolumn{1}{c}{ Model } & Sum of Squares & $d f$ & Mean Square & $F$ & $p$ \\
\hline 1 Regression & 249.181 & 5 & 49.836 & 25.027 & $0.000 \mathrm{~b}$ \\
Residual & 953.842 & 479 & 1.991 & & \\
Total & 1203.023 & 484 & & & \\
& & & & & \\
2 & & & & & \\
Regression & 300.142 & 8 & 37.518 & & \\
Residual & 902.881 & 476 & 1.897 & & \\
Total & 1203.023 & 484 & & & \\
\hline
\end{tabular}

a Dependent Variable: Intent to Seek Help at School.

b Predictors: Past Behavior, Mental Health Literacy, Internalizing \& Externalizing Symptoms

c Predictors: Past Behavior, Mental Health Literacy, Internalizing \& Externalizing Symptoms, ATT, SN, PBC

\section{Research Question 3}

An independent samples t-test was used to see whether males and females differed in their willingness to seek help at school. Consistent with our prediction, the results of the analysis revealed males were less likely to seek help at school than were their female counterparts $(t=-$ 3.252; $p=0.001$; equal variances not assumed). Further, a statistically significant difference was observed in willingness to seek help at school between males, females, and those who identify as gender-diverse/non-conforming or "other" $(F=8.913 ; p=0.000)$. Males reported the lowest likelihood to seek help of the three categories $(M=1.80 ; S D=1.342)$, followed by females $(M=$ 2.25; $S D=1.661)$. Those who identified as gender-diverse/non-conforming or "other" reported the highest likelihood to seek help of all three groups $(M=3.21 ; S D=2.293)$.

Three separate simple mediations were conducted to assess whether subscales of conformity to masculine norms could explain the difference in binary sex categories' (i.e., male and female) intent to seek help at school. The results of the mediation tests can be found in Table 7. Contrary to our prediction, Risk-Taking and Self-Reliance, were not statistically significant 
mediators in our model ( $p=0.968$ and 0.680 , respectively). However, according to prediction, Emotional Control was a significant predictor in our model $(p=0.023)$.

Table 7. Mediation

\begin{tabular}{lccc}
\hline & \multicolumn{2}{c}{ Test Statistic } & \\
\cline { 2 - 3 } Source of Mediation & $F$ & Sobel Statistic & $p$ \\
\hline Risk-Taking & 10.123 & & 0.002 \\
Step 1 & 15.942 & & 0.000 \\
Step 2 & 6.016 & & 0.003 \\
Step 3 & & -1.34 & 0.164 \\
Step 4 & & \\
Self-Reliance & 10.123 & \\
Step 1 & 0.063 & & 0.002 \\
Step 2 & 5.818 & & 0.803 \\
Step 3 & & 0.245 & 0.003 \\
Step 4 & & 0.806 \\
Emotional Control & & \\
Step 1 & & \\
Step 2 & 10.123 & & 0.002 \\
Step 3 & 13.723 & & 0.000 \\
Step 4 & 6.174 & & 0.002 \\
\end{tabular}

Note: Step 1 refers to the effect of the predictor (student sex) on the outcome (intent to seek help at school). Step 2 refers to the effect of the predictor (student sex) on the mediator (risk-taking, self-reliance, or emotional control). Step 3 is a test of the predictor (student sex) on the outcome (intent to seek help at school), controlling for the mediator (risk-taking, self-reliance, or emotional control). Step 4 refers to the Sobel Test of significance of the mediation model (Sobel, 1982). 


\section{DISCUSSION}

To our knowledge, this study was the first to examine high school students' willingness to seek help at school. In addition to our examination of help-seeking at school, we were interested in high schoolers' preferences for help-seeking source when they have internalizing problems. Consistent with previous research, we found that overall, students preferred to seek help from informal sources, with the highest preferences reported for friends, partners (i.e., boy/girlfriend) and parents, in that order. Also, we found significant differences in help-seeking source preference between those with and without risk for internalizing problems. Students who endorsed internalizing symptoms were significantly more likely to report they would not seek help than did their peers without internalizing symptoms. This discrepancy was found amongst all sources of support, and statistically significant for the following sources: parent, non-parent family member, teacher, helpline, religious leader, and youth worker/mentor. Interestingly, students with elevated internalizing symptoms reported the third highest likelihood was to not seek help, preceded only by choices of a friend or boy/girlfriend. Therefore, our findings suggest that students exhibiting internalizing symptoms are less likely to seek help when they most need it. This finding further reinforces the urgency for school systems to develop and strengthen their mental health screening and treatment capacities at the secondary level. Though research has shown that, generally speaking, greater symptom severity is associated with greater help-seeking intent, research on internalizing problems specifically reveals the opposite (Magaard, Seeralan, Schulz, \& Brütt, 2017). This negative correlation is likely related to the symptom-pattern associated with internalizing symptoms; a pattern which includes behavioral inhibition, a lack of motivation, and anxiety around social interactions. 
A central aim of this study was to examine the utility of TPB in our understanding of high school students' help-seeking intent. Consistent with our hypothesis, the addition of variables associated with the TPB added significant value above those variables previously identified in research (i.e., sex, symptom severity, externalizing symptoms, mental health literacy, and past behavior). However, inconsistent with previous studies (e.g., Groth, \& Schultze-Lutter, 2017), ATT was not the most important TPB variable in our regression model. In fact, $\mathrm{PBC}$ was the only TPB variable with significant weight in our regression model. This finding is of particular interest as it suggests adolescents may still endorse significant barriers to help-seeking at school. Though many associated barriers to mental health treatment are eliminated in the school, our particular sample still reported significant barriers to treatment. Importantly, the TPB emphasizes that barriers need not be actual, and that even the perception of barriers can impede one's behavioral intent and subsequent behavioral engagement. Although the perception of behavioral control affected students' intent to seek help in this sample, this perception is also amenable to intervention. Additionally, only internalizing symptoms and past behavior were significant weights in the first step of our regression model. Specifically, previous engagement in mental health treatment was associated with greater intent to seek help at school and greater internalizing symptom severity was associated with less intent to seek help at school. Contrary to previous findings, mental health literacy, student sex, and externalizing symptoms were not significant independent contributors.

We investigated whether males and females differed in their willingness to seek help at school. Consistent with much prior research (e.g., Alloy et al., 2016), males endorsed significantly less intent to seek help than their female counterparts. We conducted three separate mediation models with three subscales from a measure of conformity to masculine norms in an 
attempt to explain this difference in help-seeking intent by sex. Inconsistent with our hypotheses, measures of Risk-Taking, Self-Reliance did not return significant mediation results of intent by sex. In fact, the results of our study did not find an association between student sex and our measure of Self-Reliance, suggesting that this study sample did not significantly differ by sex in their preferences for independent problem-solving. Even though more males endorsed a preference for risk than females, this difference did not significantly explain their differences in willingness to seek help at school. Consistent with our prediction, a measure of Emotional Control (i.e., emotional suppression or repression) did significantly mediate the association between student sex and intent to seek help. This suggests that, at least in part, it is males' preference not to share their feelings or emotions with others that prevents them from seeking help. Accordingly, females were much more likely to endorse items related to emotional openness, including the idea that sharing one's feelings is important and enjoyable, and thus, more likely to seek help. This finding reveals some practical implications of gender role socialization as it suggests females are more likely comfortable speaking about and expressing their symptoms and feelings. On the other hand, males are socialized to be more stoic and constricted in terms of their emotional expression, a result of socializing against expressions of emotional sensitivity (Brody, 2000). Our study also revealed another noteworthy trend related to gender in that students who reported being gender-diverse/non-conforming reported significantly greater willingness to seek help at school than both males and females. Concordant with our previous explanation of help-seeking intent by gender, it is likely that those who are gender nonconforming are, by definition, more rejecting of binary gender norms (i.e., non-conforming), and are therefore less likely to abide by gender role socialization that may restrict emotional expression. This is consistent with previous research that identifies greater mental health 
treatment use by gender-nonconforming individuals (McNair \& Bush, 2016). Additionally, gender-diverse students were more likely than their gender binary or cis-gender counterparts to endorse significant internalizing problems, a trend that is widely observed and cited (Clark et al., 2014; American Psychological Association, 2015). Not only did the males in this sample report significantly less help-seeking intent, but they also endorsed significantly fewer internalizing symptoms than their female and non-binary peers. Therefore, future research should focus on male students' help-seeking trends when they have significant internalizing problems. Future research could focus on males' preferences for a variety of help-seeking solutions that are less emotion-focused and respect a preference for emotional control. Indeed, there are many successful therapies that are solutions-focused (e.g., behavioral activation; Simmonds-Buckley, Kellett, \& Waller, 2019) and do not necessarily address cognitive correlates of internalizing disorders. Additionally, future research could test the effectiveness of interventions aimed at promoting emotional openness (and reducing emotional control) for males in an effort to increase the acceptability of, and subsequent willingness to engage in mental health treatment.

\section{Limitations}

This study has some limitations that should be addressed in future research. First, our study was survey-based and cross-sectional providing no opportunity for an actual measure of behavior. Therefore, our results are based on students' assessment of their likelihoods to seek help from a variety of sources, but not their actual engagement with any one source. Therefore, this study would be strengthened by an actual measure of mental health help-seeking behavior. However, many of our study's findings were concordant with the extant literature base on adolescent help-seeking, and further provided interesting trends for adolescents at-risk for internalizing problems. Additionally, this study is limited by its use of short mental health 
assessments, that are not diagnostic in nature, but rather, intended as a universal screening tools (Renshaw \& Cook, 2016 \& 2018). Future research should include follow-up assessments for internalizing problems, which would not only allow for an examination of clinically significant levels of internalizing problems, but may also reveal trends specific to a given disorder (e.g., anxiety vs. depression, etc.) This study would also be strengthened by a differentiation in our assessment of past behavior. Our study only asked students whether they had previously engaged or were currently engaged in mental health treatment. Thus, it is possible that those who said they had previously engaged in treatment were also currently receiving help and would not need to engage in any novel help-seeking, thus limiting the strength of the past behavior-intent association. However, our findings revealed past behavior to be significantly associated with greater intent to seek help and therefore would only be strengthened with the previous assumption. Our study identified an interesting trend in help-seeking by gender identity, with those students who reported being gender diverse, non-conforming, fluid, transgender, etc. endorsing greater help-seeking intentions. It is a limitation of this study that we did not have a greater sample of gender diverse students to further examine this trend with the acknowledgement that the students appearing in our non-binary category actually represent many different identities, not just one homogenous group. A final limitation is the lack of study generalizability due to our measures and study sample. Our sample was predominantly White, and participants all attended the same high school. Furthermore, it is likely our results are affected by a selection bias, in that the participating school was receptive towards and capable of participating in a project of this scale and magnitude. It is possible these results are affected by the particular context of the school from which we studied. Therefore, more research is required on differing and diverse samples to assess the generalizability of this study's findings. 


\section{Concluding Statement}

In October 2019 the Center for Disease Control (CDC) revealed that in 2017, suicide was the second most common cause of death for individuals' ages 10-14. The rate of suicide for this age group had increased $56 \%$ in the less than two decades, surpassing deaths by homicide in the latest reporting year. In light of the recent national data, a focus on adolescent mental health is more important than ever. Up to one-third of adolescents nationwide, and $39 \%$ of our study sample are at risk for internalizing problems. Characterized by negative feelings about oneself, sadness, nervousness, tension, irritability and more, internalizing disorders are particularly challenging to identify in schools. Not only are current methods for identifying mental health problems in schools like mental health screeners and office discipline referrals applied inconsistently, but they are not guaranteed to offer the appropriate and necessary help to those students in need. Further, students with internalizing disorders are generally less disruptive, bothersome, and noisy than their externalizing counterparts. And although adolescents with internalizing symptoms may have impaired social and/or academic functioning, these impairments are generally less visible than those for students exhibiting the more noticeable externalizing symptoms. Fortunately, adolescents are also able to self-identify at school, given in part by their placement on a developmental path toward maturation. Adolescents are capable of abstract thought, expression, and as such, are offered accompanying responsibilities. These responsibilities may include advocating for one's needs, be them academic, social or behavioral. However, it is apparent that many adolescents fail to identify their needs when they may benefit most from the help of a school psychologist, counselor or social worker. For these reasons, studies that consider why adolescents do or do not seek help for their mental health problems are 
essential for optimizing pathways to treatment for youth at school in order to avoid the deleterious effects of untreated mental health problems. 


\section{REFERENCES}

Addis, M. E., \& Mahalik, J. R. (2003). Men, masculinity, and the contexts of help seeking. American Psychologist, 58, 5. doi:10.1037/0003-066X.58.1.5

Ajzen, I. (1985). From intentions to action: A theory of planned behavior. In J. Kuhl \& J. Beckman (Eds.), Action control: From cognitions to behaviors (pp. 11-39). New York, NY: Springer. doi:10.1-7/978-3-642-69746-3_2

Ajzen, I. (1991). The theory of planned behavior. Organizational Behavior and Human Decision Processes, 50, 179-211. doi:10.1016/0749-5978(91)90020-T

Ajzen, I. (2002). Perceived behavioral control, self-efficacy, locus of control, and the theory of planned behavior 1. Journal of Applied Social Psychology, 32, 665-683. doi:10.1111/j.1559-1816.2002.tb00236.x

Ajzen, I. (2006). Constructing a theory of planned behavior questionnaire.

Alloy, L. B., Hamilton, J. L., Hamlat, E. J., \& Abramson, L. Y. (2016). Pubertal development, emotion regulatory styles, and the emergence of sex differences in internalizing disorders and symptoms in adolescence. Clinical Psychological Science, 4, 867-881. doi:10.1177/2167702616643008

American Psychological Association. (2015). Guidelines for psychological practice with transgender and gender nonconforming people. American Psychologist, 70(9), 832-864. doi:10.1037/a0039906

Armitage, C. J., \& Conner, M. (2001). Efficacy of the theory of planned behaviour: A metaanalytic review. British Journal of Social Psychology, 40, 471-499.

doi:10.1348/014466601164939

Arria, A. M., Winick, E. R., Garnier-Dykstra, L. M., Vincent, K. B., Caldeira, K. M., Wilcox, H. C., \& O'Grady, K. E. (2011). Help seeking and mental health service utilization among college students with a history of suicide ideation. Psychiatric Services, 62, 1510-1513. doi:10.1176/appi.ps.005562010

Baron, R. M., \& Kenny, D. A. (1986). The moderator-mediator variable distinction in social psychological research: Conceptual, strategic, and statistical considerations. Journal of Personality and Social Psychology, 51, 1173-1182.

Beals-Erickson, S. E., \& Roberts, M. C. (2016). Youth development program participation and changes in help-seeking intentions. Journal of Child and Family Studies, 25, 1634-1645. doi:10.1007/s 10826-015-0342-0

Bohon, L. M., Cotter, K. A., Kravitz, R. L., Cello Jr, P. C., \& Fernandez y Garcia, E. (2016). The theory of planned behavior as it predicts potential intention to seek mental health services 
for depression among college students. Journal of American College Health, 64, 593603. doi:10.1080/07448481.2016.1207646

Bradley, K. L., McGrath, P. J., Brannen, C. L., \& Bagnell, A. L. (2010). Adolescents' attitudes and opinions about depression treatment. Community Mental Health Journal, 46, 242251. doi:10.1007/s10597-009-9224-5

Brody, L. R. (2000). The socialization of gender differences in emotional expression: Display rules, infant temperament, and differentiation. Gender and emotion: Social psychological perspectives, 2, 24-47.

Bruffaerts, R., Demyttenaere, K., Hwang, I., Chiu, W. T., Sampson, N., Kessler, R. C., ... \& Florescu, S. (2011). Treatment of suicidal people around the world. The British Journal of Psychiatry, 199, 64-70. doi:10.1192/bjp.bp.110.084129

Buckner, J. D., \& Schmidt, N. B. (2009). A randomized pilot study of motivation enhancement therapy to increase utilization of cognitive-behavioral therapy for social anxiety. Behaviour Research and Therapy, 47, 710-715. doi:10.1016/j.brat.2009.04.009

Cakar, F. S., \& Savi, S. (2014). An exploratory study of adolescent's help-seeking sources. Procedia-Social and Behavioral Sciences, 159, 610-614. doi:10.1007/s40894017-0078-8

Clement, S., Schauman, O., Graham, T., Maggioni, F., Evans-Lacko, S., Bezborodovs, N., ... \& Thornicroft, G. (2015). What is the impact of mental health-related stigma on helpseeking? A systematic review of quantitative and qualitative studies. Psychological Medicine, 45, 11-27. doi:10.1017/S0033291714000129

Clark, T. C., Lucassen, M. F., Bullen, P., Denny, S. J., Fleming, T. M., Robinson, E. M., \& Rossen, F. V. (2014). The health and well-being of transgender high school students: results from the New Zealand adolescent health survey (Youth'12). Journal of Adolescent Health, 5593-99. doi: 10.1016/j.jadohealth.2013.11.008

Cohen, Jacob. (1988). Statistical power analysis for the behavioral sciences (2nd ed.). New York, NY: Academic Press.

Cramer, K. M. (1999). Psychological antecedents to help-seeking behavior: A reanalysis using path modeling structures. Journal of Counseling Psychology, 46, 381. doi:10.1037/00220167.46.3.381

Dean, K. E., Long, A. C., Matthews, R. A., \& Buckner, J. D. (2018). Willingness to seek treatment among Black students with anxiety or depression: The synergistic effect of sociocultural factors with symptom severity and intolerance of uncertainty. Behavior therapy, 49, 691-701. doi:10.1016/j.beth.2017.12.008 
Divin, N., Harper, P., Curran, E., Corry, D., \& Leavey, G. (2018). Help-Seeking Measures and Their Use in Adolescents: A Systematic Review. Adolescent Research Review, 1-10. doi:10.1007/s40894-017-0078-8

Downs, M. F., \& Eisenberg, D. (2012). Help seeking and treatment use among suicidal college students. Journal of American College Health, 60, 104-114. doi:10.1080/07448481.2011.619611

Fergusson, D. M., \& Woodward, L. J. (2002). Mental health, educational, and social role outcomes of adolescents with depression. Archives of general psychiatry, 59, 225-231. doi:10.1001/archpsyc.59.3.225

Field, A. (2013). Discovering statistics using IBM SPSS statistics. sage.

Gilliom, M., \& Shaw, D. S. (2004). Codevelopment of externalizing and internalizing problems in early childhood. Development and Psychopathology, 16, 313-333.

Godin, G., \& Kok, G. (1996). The theory of planned behavior: A review of its applications to health-related behaviors. American journal of health promotion, 11, 87-98. doi:10.4278/0890-1171-11.2.87

Gulliver, A., Griffiths, K. M., \& Christensen, H. (2010). Perceived barriers and facilitators to mental health help-seeking in young people: A systematic review. BMC psychiatry, 10, 1-9. doi:10.1186/1471-244X-10-113v

Hagger, M. S., Polet, J., \& Lintunen, T. (2018). The reasoned action approach applied to health behavior: Role of past behavior and tests of some key moderators using meta-analytic structural equation modeling. Social Science \& Medicine, 213, 85-94. doi:10.1016/j.socscimed.2018.07.038

Himmelstein, M. S., \& Sanchez, D. T. (2016). Masculinity impediments: Internalized masculinity contributes to healthcare avoidance in men and women. Journal of Health Psychology, 21, 1283-1292. doi:10.1177/1359105314551623

Hom, M. A., Stanley, I. H., \& Joiner Jr, T. E. (2015). Evaluating factors and interventions that influence help-seeking and mental health service utilization among suicidal individuals: A review of the literature. Clinical Psychology Review, 40, 28-39. doi:10.1016/j.cpr.2015.05.006

Horwitz, A. G., Czyz, E. K., \& King, C. A. (2015). Predicting Future Suicide Attempts Among Adolescent and Emerging Adult Psychiatric Emergency Patients. Journal of Clinical Child \& Adolescent Psychology, 44, 751-761. doi:10.1080/15374416.2014.910789

Juvrud, J., \& Rennels, J. L. (2017). "I Don't Need Help": Gender Differences in how Gender Stereotypes Predict Help-Seeking. Sex Roles, 76, 27-39. doi:10.1007/s11199-016-0653-7 
Kalberg, J. R., Lane, K. L., \& Menzies, H. M. (2010). Using systematic screening procedures to identify students who are nonresponsive to primary prevention efforts: Integrating academic and behavioral measures. Education and Treatment of Children, 561-584. doi:10.1353/etc.2010.0007

Kessler, R. C., Chiu, W. T., Demler, O., \& Walters, E. E. (2005). Prevalence, severity, and comorbidity of 12-month DSM-IV disorders in the National Comorbidity Survey Replication. Archives of General Psychiatry, 62, 617-627. doi:10.1001/archpsyc.62.6.617

Kuhl, J., Jarkon-Horlick, L., \& Morrissey, R. F. (1997). Measuring barriers to help-seeking behavior in adolescents. Journal of Youth and Adolescence, 26, 637-650. doi:10.1023/A:1022367807715

Leshem, B., Haj-Yahia, M. M., \& Guterman, N. B. (2015). The characteristics of help seeking among Palestinian adolescents following exposure to community violence. Children and Youth Services Review, 49, 1-10. doi:10.1016/j.childyouth.2014.12.022

Li, W., Dorstyn, D. S., \& Denson, L. A. (2014). Psychosocial correlates of college students' help-seeking intention: A meta-analysis. Professional Psychology: Research and Practice, 45, 163-170. doi:10.1037/a0037118

Lindsey, M. A., Korr, W. S., Broitman, M., Bone, L., Green, A., \& Leaf, P. J. (2006). HelpSeeking Behaviors and Depression among African American Adolescent Boys. Social Work, 51, 49-58. doi:10.1093/sw/51.1.49

Long, A. C. J., \& Maynard, B. R. (2014). Treatment integrity as adult behavior change: A review of theoretical models. Treatment integrity: A foundation for evidence-based practice in applied psychology. Washington, DC: American Psychological Association.

Magaard, J. L., Seeralan, T., Schulz, H., \& Brütt, A. L. (2017). Factors associated with helpseeking behaviour among individuals with major depression: A systematic review. PLoS One, 12, e0176730. doi:10.1371/journal.pone.0176730

Mahalik, J. R., Locke, B. D., Ludlow, L. H., Diemer, M. A., Scott, R. P., Gottfried, M., \& Freitas, G. (2003). Development of the Conformity to Masculine Norms Inventory. Psychology of Men \& Masculinity, 4, 3-25. doi:10.1037/1524-9220.4.1.3

McNair, R. P., \& Bush, R. (2016). Mental health help seeking patterns and associations among Australian same sex attracted women, trans and gender diverse people: a survey-based study. BMC psychiatry, 16, 209. doi:10.1186/s12888-016-0916-4

Merikangas, K. R., He, J. P., Burstein, M., Swanson, S. A., Avenevoli, S., Cui, L., ... \& Swendsen, J. (2010). Lifetime prevalence of mental disorders in US adolescents: results from the National Comorbidity Survey Replication-Adolescent Supplement (NCS- 
A). Journal of the American Academy of Child \& Adolescent Psychiatry, 49, 980-989. doi:10.1016/j.jaac.2010.05.017

Naser, S., Brown, J., \& Verlenden, J. (2018). The utility of universal screening to guide schoolbased prevention initiatives: Comparison of office discipline referrals to standardized emotional and behavioral risk screening. Contemporary School Psychology. Advance online publication. doi:10.1007/s40688-018-0173-2

Ouellette, J. A., \& Wood, W. (1998). Habit and intention in everyday life: The multiple processes by which past behavior predicts future behavior. Psychological Bulletin, 124, 54-74. doi:10.1037/0033-2909.124.1.54

Prochaska, J. D., Le, V. D., Baillargeon, J., \& Temple, J. R. (2016). Utilization of professional mental health services related to population-level screening for anxiety, depression, and post-traumatic stress disorder among public high school students. Community Mental Health Journal, 52, 691-700. doi:10.1007/s10597-015-9968-z

Rickwood, D., Deane, F. P., Wilson, C. J., \& Ciarrochi, J. (2005). Young people's help-seeking for mental health problems. Australian e-journal for the Advancement of Mental Health, 4, 218-251. doi:10.5172/jamh.4.3.218

Rise, J., Sheeran, P., \& Hukkelberg, S. (2010). The role of self-identity in the theory of planned behavior: A meta-analysis. Journal of Applied Social Psychology, 40, 1085-1105. doi:10.1111/j.1559-1816.2010.00611.x

Schnyder, N., Panczak, R., Groth, N., \& Schultze-Lutter, F. (2017). Association between mental health-related stigma and active help-seeking: Systematic review and meta-analysis. The British Journal of Psychiatry, 210, 261-268. doi:10.1192/bjp.bp.116.189464

Severson, H. H., Walker, H. M., Hope-Doolittle, J., Kratochwill, T. R., \& Gresham, F. M. (2007). Proactive, early screening to detect behaviorally at-risk students: Issues, approaches, emerging innovations, and professional practices. Journal of School Psychology, 45, 193-223. doi:10.1016/j.jsp.2006.11.003

Sheeran, P., \& Taylor, S. (1999). Predicting Intentions to Use Condoms: A Meta-Analysis and Comparison of the Theories of Reasoned Action and Planned Behavior 1. Journal of Applied Social Psychology, 29, 1624-1675. doi:10.1111/j.1559-1816.1999.tb02045.x

Simmonds-Buckley, M., Kellett, S., \& Waller, G. (2019). Acceptability and Efficacy of Group Behavioral Activation for Depression Among Adults: A Meta-Analysis. Behavior Therapy. doi: 10.1016/j.beth.2019.01.003

Simpson, E. G., Vannucci, A., \& Ohannessian, C. M. (2018). Family functioning and adolescent internalizing symptoms: A latent profile analysis. Journal of Adolescence, 64, 136-145. doi:10.1016/j.adolescence.2018.02.004 
Singh, S., Zaki, R. A., \& Farid, N. D. N. (2019). A systematic review of depression literacy: Knowledge, help-seeking and stigmatising attitudes among adolescents. Journal of Adolescence, 74, 154-172. doi:10.1016/j.adolescence.2019.06.004

Sobel, M. E. (1982). Asymptotic confidence intervals for indirect effects in structural equation models. Sociological Methodology, 13, 290-312. doi:10.2307/270723

Splett, J. W., Trainor, K. M., Raborn, A., Halliday-Boykins, C. A., Garzona, M. E., Dongo, M. D., \& Weist, M. D. (2018). Comparison of Universal Mental Health Screening to Students Already Receiving Intervention in a Multitiered System of Support. Behavioral Disorders, 43, 344-356. doi:10.1177/0198742918761339

Steinfeldt, J. A., \& Steinfeldt, M. C. (2010). Gender role conflict, athletic identity, and helpseeking among high school football players. Journal of Applied Sport Psychology, 22, 262-273. doi:10.1080/10413201003691650

Sulkowski, M. L., Joyce, D. K., \& Storch, E. A. (2012). Treating Childhood Anxiety in Schools: Service Delivery in a Response to Intervention Paradigm. Journal of Child and Family Studies, 21, 938-947. doi:10.1007/s10826-011-9553-1

Swords, L., Hennessy, E., \& Heary, C. (2011). Adolescents' beliefs about sources of help for ADHD and depression. Journal of Adolescence, 34, 485-492. doi:10.1111/camh.12266

Tandon, M., Cardeli, E., \& Luby, J. (2009). Internalizing Disorders in Early Childhood: A Review of Depressive and Anxiety Disorders. Child and Adolescent Psychiatric Clinics of North America, 18, 593-610. doi:10.1016/j.chc.2009.03.004

Turner, E. A. (2012). The parental attitudes toward psychological services inventory: Adaptation and development of an attitude scale. Community mental health journal, 48, 436-449. doi:10.1007/s10597-011-9432-7

Vogel, D. L., Armstrong, P. I., Tsai, P., Wade, N. G., Hammer, J. H., Efstathiou, G., \& ... Topkaya, N. (2013). Cross-cultural validity of the Self-Stigma of Seeking Help (SSOSH) scale: Examination across six nations. Journal of Counseling Psychology, 60, 303-310. doi:10.1037/a0032055

Walker, D. M., Bell, M. R., Flores, C., Gulley, J. M., Willing, J., \& Paul, M. J. (2017). Adolescence and reward: Making sense of neural and behavioral changes amid the chaos. The Journal of Neuroscience, 37, 10855-10866. doi:10.1523/jneurosci.183417.2017

Wei, Y., McGrath, P. J., Hayden, J., \& Kutcher, S. (2015). Mental health literacy measures evaluating knowledge, attitudes and help-seeking: A scoping review. BMC psychiatry, 15, 1-20. doi:10.1186/s12888-015-0681-9 
Weidman, A. C., Augustine, A. A., Murayama, K., \& Elliot, A. J. (2015). Internalizing symptomatology and academic achievement: Bi-directional prospective relations in adolescence. Journal of Research in Personality, 58, 106-114.

doi:10.1016/j.jrp.2015.07.005

Wilson, C. J., Deane, F. P., Ciarrochi, J., \& Rickwood, D. (2005). Measuring help-seeking intentions: Properties of the general help-seeking questionnaire. Canadian Journal of Counselling, 39, 15-28. Retrieved from http://ro.uow.edu.au/hbspapers/1527

Wilson, C. J., \& Deane, F. P. (2010). Help-negation and suicidal ideation: the role of depression, anxiety and hopelessness. Journal of Youth and Adolescence, 39, 291-305. doi:10.1007/s10964-009-9487-8

Wilson, C. J., \& Deane, F. P. (2012). Brief report: Need for autonomy and other perceived barriers relating to adolescents' intentions to seek professional mental health care. Journal of Adolescence, 35, 233-237. doi:10.1016/j.adolescence.2010.06.011

Wilson, C. J., Rickwood, D., Ciarrochi, J. V., \& Deane, F. P. (2002). Adolescent barriers to seeking professional psychological help for personal-emotional and suicidal problems. Published Proceedings, 9th Annual National Conference of Suicide Prevention Australia Inc, 1-8. Retrieved from http://ro.uow.edu.au/hbspapers/518

Wilson, C. J., Rickwood, D., \& Deane, F. P. (2007). Depressive Symptoms and Help-Seeking Intentions in Young People. Clinical Psychologist, 11, 98-107. doi:10.1080/13284200701870954

World Health Organization. (2017). Depression and other common mental disorders: Global health estimates (License: CC BY-NC-SA 3.0 IGO). Retrieved from http://www.who.int/iris/handle/10665/254610

Yap, M. B. H., Wright, A., \& Jorm, A. F. (2011). The influence of stigma on young people's help-seeking intentions and beliefs about the helpfulness of various sources of help. Social Psychiatry and Psychiatric Epidemiology, 46, 1257-1265. doi:10.1007/s00127-010-0300-5

Zeifman, R. J., Atkey, S. K., Young, R. E., Flett, G. L., Hewitt, P. L., \& Goldberg, J. O. (2015). When ideals get in the way of self-care: Perfectionism and self-stigma for seeking psychological help among high school students. Canadian Journal of School Psychology, 30, 273-287. doi:10.1177/0829573515594372 


\section{APPENDIX}

\section{Student Demographics}

Grade:

Age:

Gender identity (select one):

- Female

- Male

- Gender diverse/non-conforming

- Other:

(Note. If students don't want to say, they can select other)

Racial/Ethnic Identity (select one):

- African American or Black or Caribbean Black

- White or Caucasian

- Latino(a) or Hispanic

- Asian or Asian American

- Native American or Native or Indigenous

- Native Hawaiian or Pacific Islander

- Multi-racial or multi-ethnic

- Other:

(Note. If students don't want to say, they can select other)

\section{Past behavior:}

I have received or am currently receiving mental health treatment (e.g., counseling, therapy, behavioral support)

Select:

- 1 (Yes) or

- 0 (No) 


\section{Student Subjective Wellbeing Questionnaire}

Here are some questions about what you think, feel, and do at school. Read each sentence and choose the one best answer.

\begin{tabular}{|c|c|c|c|c|c|}
\hline & & $\begin{array}{l}\text { Almost } \\
\text { Never }\end{array}$ & $\begin{array}{l}\text { Some- } \\
\text { times }\end{array}$ & Often & $\begin{array}{l}\text { Almost } \\
\text { Always }\end{array}$ \\
\hline 1. & I get excited about learning new things in class. & 1 & 2 & 3 & 4 \\
\hline 2. & I feel like I belong at my school. & 1 & 2 & 3 & 4 \\
\hline 3. & I feel like the things I do at school are important. & 1 & 2 & 3 & 4 \\
\hline 4. & I am a successful student. & 1 & 2 & 3 & 4 \\
\hline 5. & $\begin{array}{l}\text { I am really interested in the things I am doing } \\
\text { at school. }\end{array}$ & 1 & 2 & 3 & 4 \\
\hline 6. & I can really be myself at school. & 1 & 2 & 3 & 4 \\
\hline 7. & $\begin{array}{l}\text { I think school matters and should be taken } \\
\text { seriously. }\end{array}$ & 1 & 2 & 3 & 4 \\
\hline 8. & I do good work at school. & 1 & 2 & 3 & 4 \\
\hline 9. & I enjoy working on class projects and assignments. & 1 & 2 & 3 & 4 \\
\hline 10. & I feel like people at my school care about me. & 1 & 2 & 3 & 4 \\
\hline 11. & I feel it is important to do well in my classes. & 1 & 2 & 3 & 4 \\
\hline 12. & I do well on my class assignments. & 1 & 2 & 3 & 4 \\
\hline 13. & $\begin{array}{l}\text { I feel happy when I am working and learning } \\
\text { at school. }\end{array}$ & 1 & 2 & 3 & 4 \\
\hline 14. & I am treated with respect at my school. & 1 & 2 & 3 & 4 \\
\hline 15. & $\begin{array}{l}\text { I believe the things I learn at school will help } \\
\text { me in my life. }\end{array}$ & 1 & 2 & 3 & 4 \\
\hline 16. & I get good grades in my classes. & 1 & 2 & 3 & 4 \\
\hline
\end{tabular}




\section{Youth Internalizing Problems Screener}

Here are some questions about what you think, feel, and do.

Read each sentence and choose the one best answer.

\begin{tabular}{|c|c|c|c|c|c|}
\hline & & $\begin{array}{l}\text { Almost } \\
\text { Never }\end{array}$ & $\begin{array}{l}\text { Some- } \\
\text { times }\end{array}$ & Often & $\begin{array}{l}\text { Almost } \\
\text { Always }\end{array}$ \\
\hline 1. & I feel nervous or afraid. & 1 & 2 & 3 & 4 \\
\hline 2. & I feel very tired and drained of energy. & 1 & 2 & 3 & 4 \\
\hline 3. & I find it hard to relax and settle down. & 1 & 2 & 3 & 4 \\
\hline 4. & $\begin{array}{l}\text { I get bothered by things that didn't bother } \\
\text { me before. }\end{array}$ & 1 & 2 & 3 & 4 \\
\hline 5. & $\begin{array}{l}\text { I have uncomfortable and tense feelings in } \\
\text { my body. }\end{array}$ & 1 & 2 & 3 & 4 \\
\hline 6. & I feel moody or grumpy. & 1 & 2 & 3 & 4 \\
\hline 7. & $\begin{array}{l}\text { I feel like I'm going to panic or think I might } \\
\text { lose control. }\end{array}$ & 1 & 2 & 3 & 4 \\
\hline 8. & I do not really enjoy doing anything anymore. & 1 & 2 & 3 & 4 \\
\hline 9. & $\begin{array}{l}\text { I feel worthless or lonely when I'm around } \\
\text { other people. }\end{array}$ & 1 & 2 & 3 & 4 \\
\hline 10. & I have headaches, stomachaches, or other pains. & 1 & 2 & 3 & 4 \\
\hline
\end{tabular}




\section{Youth Externalizing Problems Screener}

Here are some questions about what you think, feel, and do.

Read each sentence and circle the one best answer.

\begin{tabular}{llcccc} 
& & $\begin{array}{c}\text { Almost } \\
\text { Never }\end{array}$ & $\begin{array}{c}\text { Some- } \\
\text { times }\end{array}$ & $\begin{array}{c}\text { Often } \\
\text { 1. I lose my temper and get angry with other people. }\end{array}$ & $\begin{array}{c}\text { Almost } \\
\text { Always }\end{array}$ \\
\hline 2. I have a hard time sitting still when other people want me to. & 1 & 2 & 3 & 4 \\
\hline 3. I fight and argue with other people. & 1 & 2 & 3 & 4 \\
\hline 4. I break rules whenever I feel like it. & 1 & 2 & 3 & 4 \\
\hline 5. I talk a lot and interrupt others when they are talking. & 1 & 2 & 3 & 4 \\
\hline 6. I say or do mean things to hurt other people. & 1 & 2 & 3 & 4 \\
\hline 7. I have a hard time focusing on things that are important. & 1 & 2 & 3 & 4 \\
\hline 8. I like to annoy people or make them upset. & 1 & 2 & 3 & 4 \\
\hline 9. I get distracted by the little things happening around me. & 1 & 2 & 3 & 4 \\
\hline 10. I choose not to follow directions and don't listen to adults. & 1 & 2 & 3 & 4 \\
\hline
\end{tabular}




\section{Strength and Difficulties Questionnaire: Symptoms Impact Score}

Overall, do you think that you have difficulties in any of the following areas: emotions, concentration, behavior or being able to get on with other people?

$\begin{array}{llll}\text { Yes- } & \begin{array}{l}\text { Yes- } \\ \text { minor } \\ \text { difficulties }\end{array} & \begin{array}{l}\text { Yes- } \\ \text { difficulties } \\ \text { severe } \\ \text { difficulties }\end{array} \\ \square & \square & \square & \square\end{array}$

If you have answered "Yes", please answer the following questions about these difficulties:

- How long have these difficulties been present?

$\begin{array}{llll}\begin{array}{l}\text { Less than } \\ \text { a month }\end{array} & 1-5 & 6-12 & \text { Over } \\ \text { months } & \text { months } & \text { a year } \\ \square & \square & \square & \square\end{array}$

- Do the difficulties upset or distress you?

$\begin{array}{llll}\begin{array}{l}\text { Not } \\ \text { at all }\end{array} & \begin{array}{l}\text { Only a } \\ \text { little }\end{array} & \begin{array}{l}\text { A medium } \\ \text { amount }\end{array} & \begin{array}{l}\text { A great } \\ \text { deal }\end{array} \\ \square & \square & \square & \square\end{array}$

- Do the difficulties interfere with your everyday life in the following areas?

$\begin{array}{lllll} & \begin{array}{l}\text { Not } \\ \text { at all }\end{array} & \begin{array}{l}\text { Only a } \\ \text { little }\end{array} & \begin{array}{l}\text { A medium } \\ \text { amount }\end{array} & \begin{array}{l}\text { A great } \\ \text { deal }\end{array} \\ \text { HOME LIFE } & \square & \square & \square & \square \\ \text { FRIENDSHIPS } & \square & \square & \square & \square \\ \text { CLASSROOM LEARNING } & \square & \square & \square & \square \\ \text { LEISURE ACTIVITIES } & \square & \square & \square & \square\end{array}$

- Do the difficulties make it harder for those around you (family, friends, teachers, etc.)?

\begin{tabular}{|c|c|c|}
\hline $\begin{array}{l}\text { Not } \\
\text { at all }\end{array}$ & $\begin{array}{l}\text { Only a } \\
\text { little }\end{array}$ & $\begin{array}{l}\text { A medium } \\
\text { amount }\end{array}$ \\
\hline
\end{tabular}




\section{General Help-Seeking Questionnaire}

\section{Part 1:}

On the basis of how things have been for me over the last six months, I intend to seek mental health help from someone at my school (e.g., school counselor, school social worker, teacher, or administrator)

1 (very unlikely) to 7 (very likely)

Part 2:

Instructions: "If you were having an emotional or personal problem how likely is it that you would seek help from the following people?"

An emotional or personal problem refers to any problem related to one's mental health or wellbeing. For example, experiences of significant emotional distress or discomfort, disruptions in day-to-day functioning or behavior, or significant conflict in relationships with others. Feelings may include anger/irritability, nervousness, anxiety, sadness, depression, or loss of interest and motivation.

Partner (boy/girlfriend)

Friend

Parent

Family (non-parent)

School Counselor/Social Worker

Help line

Doctor/GP

Teacher

Pastor/Priest/Other Religious Leader

Youth worker/mentor

Would not seek help
1 (very unlikely) to 7 (very likely) 1 (very unlikely) to 7 (very likely) 1 (very unlikely) to 7 (very likely) 1 (very unlikely) to 7 (very likely) 1 (very unlikely) to 7 (very likely) 1 (very unlikely) to 7 (very likely) 1 (very unlikely) to 7 (very likely) 1 (very unlikely) to 7 (very likely) 1 (very unlikely) to 7 (very likely) 1 (very unlikely) to 7 (very likely) 1 (very unlikely) to 7 (very likely) 


\section{Parental Attitudes Toward Help-Seeking Scale Inventory (Adapted for Students)}

Instructions: "For each item, indicate whether you Strongly Disagree (1), Disagree (2), Somewhat Disagree (3), Somewhat Agree (4), Agree (5) or Strongly Agree (6)."

1. I would not want others (friends, family, teachers, etc.) to know if I had an emotional or personal problem.

2. To avoid thinking about my problems, doing other activities is a good solution.

3. Having been mentally ill carries with it feelings of shame.

4. Important people in my life would think less of me if they found out I had an emotional or personal problem.

5. Psychological problems tend to work out by themselves.

6. I would be uncomfortable seeking professional help at school because people (friends, family, teachers, etc.) might find out about it.

7. I would not want to go to a school mental health professional because of what people might think.

8. There is something admirable in the attitude of people who are willing to cope with their conflicts and fears without seeking professional help.

9. I would feel uneasy going to a school mental health professional because of what some people would think.

10. Strong willed individuals can handle emotional or personal problems without needing professional help.

11. If I received treatment for an emotional or personal problem, I would feel that it should be "kept secret".

12. I would be embarrassed if my classmate saw me going into the office of a school professional who deals with emotional or personal concerns.

13. People should work out their own problems instead of getting professional help.

14. There are things that happen in my family I would not discuss with anyone.

15. Seeking professional help is a sign of weakness.

16. Strong willed individuals can handle problems without professional help. 


\section{Conformity to Masculine Norms}

Instructions: "For each item, indicate whether you Strongly Disagree (1), Disagree (2), Somewhat Disagree (3), Somewhat Agree (4), Agree (5) or Strongly Agree (6)."

1. I hate asking for help

2. Asking for help is a sign of failure

3. I ask for help when I need it

4. I never ask for help

5. It bothers me when I have to ask for help

6. I take risks

7. In general, I do not like risky situations

8. I frequently put myself in risky situations

9. I hate any kind of risk

10. I enjoy taking risks

11. I like to talk about my feelings

12. I tend to share my feelings

13. I love to explore my feelings with others

14. I tend to keep my feelings to myself

15. Feelings are important to show 


\section{Barriers to Adolescent Seeking Help Scale- Brief}

Instructions: please rate your level of agreement with the following statements from 1 (strongly disagree) to 6 (strongly agree)

1. I would solve my problem myself.

2. I think I should work out my own problems.

3. I'd be too embarrassed to talk to a school counselor.

4. Adults can't understand adolescent problems.

5. Even if I wanted to, I wouldn't have time to see a school counselor.

6. A school counselor might make me do what I don't want to.

7. I wouldn't want my family to know I was seeking support from a school counselor.

8. I couldn't afford counseling.

9. Nothing will change the problems I have.

10. If I go to counseling, I might find out I'm crazy.

11. If I went for help, the school counselor would not keep my secret. 


\section{Mental Health Promoting Knowledge Instrument}

Instructions: Here are 10 statements about things that may be helpful for good mental health and wellbeing. On a scale from 1 (Definitely Unhelpful) to 5 (Definitely Helpful), how helpful do you believe each of the following are:

1. Handling stressful situations in a good manner.

2. Believing in yourself.

3. Having good sleep routines.

4. Making decisions based on your own will.

5. Setting limits for your own actions.

6. Feeling that you belong in a community.

7. Overcoming your own negative thinking.

8. Setting limits for what is okay for you.

9. Feeling valuable regardless of what you have accomplished.

10. Experiencing school success or mastery. 


\section{Institutional Review Board Approval}

\section{ACTION ON EXEMPTION APPROVAL REQUEST}

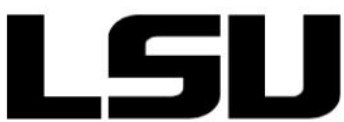

To:

$$
\text { Anna Long }
$$

Psychology

From: Dennis Landin

Chair, Institutional Review Board
Institutional Review Board Dr. Dennis Landin, Chair 130 David Boyd Hall

Baton Rouge, LA 70803

P: 225.578 .8692

F: 225.578 .5983

irb@lsu.edu

Isu.edu/research

Date: $\quad$ August 2, 2019

Re: $\quad$ IRB\# E11532

Title: $\quad$ The School Wellness Project: Mental Health Screening and Help-Seeking in Adolescence

New Protocol/Modification/Continuation: Modification

Brief Modification Description: Chang PI to Anna Long, title change, updated the description of the mental health screening, expanded the instruments, updated several other accompanying documents based on school input and what schools might be interested in the PI analyzing.

Review date: $\underline{8 / 2 / 2019}$

Approved

Approval Date: $\underline{8 / 2 / 2019} \quad$ Approval Expiration Date: $\underline{3 / 10 / 2022}$

By: Dennis Landin, Chairman DLandin

PRINCIPAL INVESTIGATOR: PLEASE READ THE FOLLOWING Continuing approval is CONDITIONAL on:

1. Adherence to the approved protocol, familiarity with, and adherence to the ethical standards of the Belmont Report, and LSU's Assurance of Compliance with DHHS regulations for the protection of human subjects*

2. Prior approval of a change in protocol, including revision of the consent documents or an increase in the number of subjects over that approved.

3. Obtaining renewed approval (or submittal of a termination report), prior to the approval expiration date, upon request by the IRB office (irrespective of when the project actually begins); notification of project termination.

4. Retention of documentation of informed consent and study records for at least 3 years after the study ends.

5. Continuing attention to the physical and psychological well-being and informed consent of the individual participants including notification of new information that might affect consent.

6. A prompt report to the IRB of any adverse event affecting a participant potentially arising from the study.

7. Notification of the IRB of a serious compliance failure.

8. SPECIAL NOTE: Make sure you use bcc when emailing more than one recipient. Approvals will automatically be closed by the IRB on the expiration date unless the PI requests a continuation.

*All investigators and support staff have access to copies of the Belmont Report, LSU's Assurance with DHHS, DHHS (45 CFR 46) and FDA regulations governing use of human subjects, and other relevant documents in print in this office or on our World Wide Web site at http://www.Isu.edu/irb 


\section{VITA}

Sam Allouche was born in Paris, France. She received her Bachelor of Science in psychology and Master of Science in behavioral health from Tulane University in New Orleans, Louisiana. Sam is a third-year doctoral student in school psychology at Louisiana State University under the supervision of Dr. Anna Long. Her clinical and research interests include enhancing mental health treatment accessibility as well as the implementation of culturally responsive practices in a school setting. Prior to attending Louisiana State University, Sam worked as an elementary yoga and mindfulness teacher and reading interventionist. 